\title{
SUPPLEMENT 1
}

\section{TRANSLATED EXCERPT FROM WORKBOOK:}

TWO EXAMPLES AND AN EMPTY INSIGHT CARD. 
MOMENT IT HELPS TO TALK ABOUT THE TREATMENT PROGRAM:

MY WIFE IS NOW LESS WORRIED WHEN I GO FOR A WALK.

Memory Cue

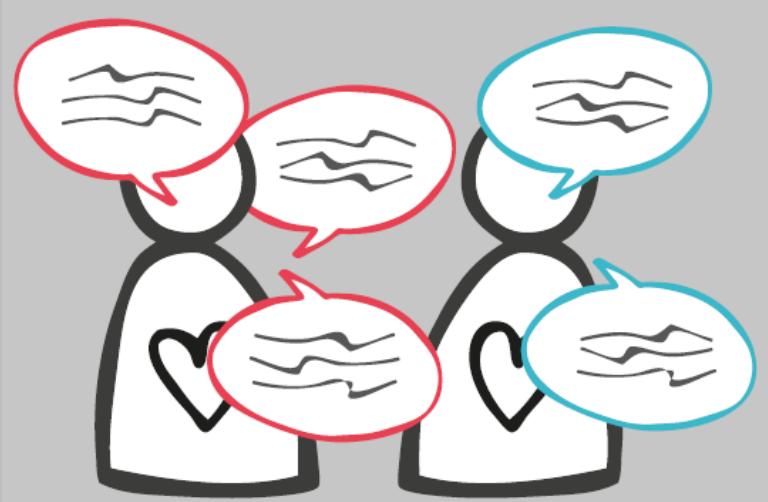

MOMENT IF I AM IN PAIN, IT DOES NOT HAVE TO MEAN THAT SOMETHING IS BROKEN OR INJURED.

\section{Memory Cue}

\section{HURT $\neq$ HARM}




\section{MOMENT}

MEMORY CUE 